\title{
Standards for Children's Height at Ages 2-9 Years Allowing for Height of Parents
}

\author{
J. M. TANNER, H. GOLDSTEIN, and R. H. WHITEHOUSE \\ From the Department of Growth and Development, Institute of Child Health, University of London
}

\begin{abstract}
Tanner, J. M., Goldstein, H., and Whitehouse, R. H. (1970). Archives of Disease in Childhood, 45, 755. Standards for children's height at ages 2-9 years allowing for height of parents. Charts ${ }^{\star}$ are presented which give centile standards for boys' and girls' heights at ages 2 to 9 when parents' height is allowed for. Mid-parent height is used (i.e. the average of father's and mother's height).

A comparison is made with results from the existing 'parent-unknown' British standard charts. A child at the 3rd centile on the parent-unknown charts is (i) at the 20 th centile on the new charts if his parents are small enough to average 3 rd centile for adults, (ii) at about the 1 st centile if his parents average the 97 th centile. Conversely a child with 97th centile parents has only to be at the 25 th centile for the population in the parent-unknown charts to be at the conventional 3rd centile limit of normal when parental height is allowed for. Thus the new standards result in considerably increased precision.

Examples are given of normal boys with small parents who piotted outside the 3 rd centile on the conventional charts but inside on the present charts. The differential diagnosis of genetic small stature is made considerably more straightforward by the use of these charts.

The correlation coefficients are given at successive ages, from 1 month to 9 years, for child's supine length or height with mid-parent height and for mother-daughter, mother-son, father-daughter, and father-son relationships.
\end{abstract}

Current standards for the height attained by a child at a given age (e.g. Tanner, Whitehouse, and Takaishi, 1966) make no allowance for the height of his parents. We know, however, that tall parents in general produce tall children and short parents short children. If a child is at the 5 th centile for height, therefore, it makes a considerable difference whether his parents are themselves 5 th centile persons (in which case he is probably normal) or whether they are 95th centile persons (in which case he is almost certainly pathologically small).

This paper gives standards which allow for parental height. They apply at present only to children aged 2.0 to 9.0 years, since earlier and later ages require separate treatment. These standards are more powerful than the 'parentunknown' standards in the sense of being able to

\section{Received 8 June 1970}

* Source of Charts. The charts are available from Creaseys Ltd. Bull Plain, Hertford, Herts. detect cases of pathological short stature (a term preferable to dwarism in the ears of parents) where this might not have been suspected and in giving a more solid basis to the diagnosis 'genetic small stature'. In theory, further refinements could be made by allowing additionally for the heights of sibs, uncles, aunts, and grandparents. Grown-up sibs contribute as much useful information as parents, but aunts, uncles, and grandparents contribute only half as much, in addition to their heights being probably less accurately recorded or recalled. Further refinements would, therefore, fairly rapidly lead to diminishing returns.

The standards given are for British children, and the means and standard deviations at each age have been taken from the current standards of Tanner et al. (1966). The regressions of child's height on parents' height however come from a collaborative international study in which children are being followed longitudinally from birth to adulthood in Brussels, London, Paris, Stockholm, Zürich, and 
Dakar. The studies are co-ordinated by the International Children's Centre, Paris through the agency of Dr. Natalie Masse and Dr. F. Falkner. The present regression data are from the London, Brussels, Stockholm, and Zurich studies, the last three by kind permission of Professor M. Graffar and Dr. Monique Asiel, Professor P. Karlberg, and Professor A. Prader. A preliminary account of some aspects of this work was included in a communication to the International Paediatric Congress in 1968 (Tanner et al., 1968).

\section{Material}

The heights of the children aged 3 and over, and of the parents, were in all instances measured on a stadiometer by a trained investigator. No reported heights of parents were used. At age 2 supine length (which averages approximately $1.0 \mathrm{~cm}$. more than standing height) was measured. The data were carefully scrutinized and any clear errors of measurement or recording were deleted.

The numbers of parents, with the mean mid-parental heights and mother-father correlations are given in Table I. Mid-parent height is simply the average of mother's and father's height. The number of children at each age are shown in Table II. All children included were measured within 2 weeks of their birthday; thus the 3-year-old class represents children of exactly 3.0 years.

\section{TABLE I}

Number of Parents Measured in Each Study, with Mid-parent Mean Heights and Correlation between Parents' Heights

\begin{tabular}{l|c|c|c|c|c}
\hline & Mothers & Fathers & $\begin{array}{c}\text { Mid-parent } \\
\text { (i.e. both } \\
\text { measured) }\end{array}$ & $\begin{array}{c}\text { Mean } \\
\text { parent } \\
\text { height } \\
\text { (cm.) }\end{array}$ & $\begin{array}{c}\text { Correlation } \\
\text { M-F }\end{array}$ \\
\hline Brussels & 52 & 48 & 41 & $167 \cdot 0$ & $0 \cdot 35$ \\
London & 84 & 56 & 55 & $166 \cdot 9$ & $0 \cdot 13$ \\
Stockholm & 144 & 116 & 114 & $170 \cdot 2$ & $0 \cdot 37$ \\
Zurich & 238 & 23 & 19 & $168 \cdot 7$ & $0 \cdot 20$ \\
Total & 518 & 243 & 229 & $168 \cdot 9$ & $0 \cdot 30$ \\
\hline
\end{tabular}

\section{Construction of Standards}

The method requires first that the height of the children at each age shall be predicted from the height of their fathers and mothers by regression. The residual variation around the regression line of children's height on parents' height is then used to calculate the centiles for all parental heights. Boys and girls have been treated separately throughout.

Let $y$ be the child's height at a given age, and $x$ the mid-parent height. Then at each age the linear equation $y=a+\beta x$ was fitted using the pooled data from all the studies. Mid-parent height was used, since at each age multiple regression equations of child's height on
TABLE II

Correlation Coefficients of Supine Length (above the line) or Stature (below the line) with Mid-Parent Height (numbers of pairs in brackets)

\begin{tabular}{|c|c|c|c|c|c|c|c|}
\hline \multicolumn{4}{|c|}{ Age (yr.) } & \multicolumn{2}{|c|}{ Boys } & \multicolumn{2}{|c|}{ Girls } \\
\hline $\begin{array}{l}0 \cdot 083 \\
0 \cdot 25 \\
0 \cdot 50 \\
0 \cdot 75 \\
1 \cdot 0 \\
1 \cdot 5 \\
2 \cdot 0 \\
3 \cdot 0 \\
4 \cdot 0\end{array}$ & $\begin{array}{l} \\
\\
\ldots \\
\ldots \\
\ldots \\
\ldots\end{array}$ & $\begin{array}{l}\ldots \\
\ldots \\
\ldots \\
\ldots \\
\ldots \\
\ldots \\
\ldots \\
\ldots \\
\ldots\end{array}$ & $\begin{array}{l}\cdots \\
\ldots \\
\ldots \\
\ldots \\
\cdots \\
\ldots \\
\cdots \\
\ldots\end{array}$ & $\begin{array}{l}0.22 \\
0.39 \\
0.44 \\
0.41 \\
0.52 \\
0.48 \\
0.49 \\
0.61 \\
0.57\end{array}$ & $\begin{array}{l}(125) \\
(140) \\
(141) \\
(145) \\
(139) \\
(125) \\
(131) \\
(128) \\
(134)\end{array}$ & $\begin{array}{l}0.28 \\
0.34 \\
0.43 \\
0.41 \\
0.41 \\
0.46 \\
0.46 \\
0.47 \\
0.51\end{array}$ & $\begin{array}{r}(103) \\
(103) \\
(110) \\
(102) \\
(102) \\
(92) \\
(96) \\
(88) \\
(95)\end{array}$ \\
\hline $\begin{array}{l}3 \cdot 0 \\
4 \cdot 0 \\
5 \cdot 0 \\
6 \cdot 0 \\
7 \cdot 0 \\
8 \cdot 0 \\
9 \cdot 0\end{array}$ & $\begin{array}{l}\ldots \\
\ldots \\
\cdots \\
\ldots \\
\ldots \\
\ldots\end{array}$ & $\begin{array}{l}\cdots \\
\cdots \\
\cdots \\
\cdots \\
\cdots \\
\ldots\end{array}$ & $\begin{array}{l}\cdots \\
\cdots \\
\cdots \\
\cdots \\
\cdots \\
\cdots\end{array}$ & $\begin{array}{l}0.57 \\
0.54 \\
0.58 \\
0.49 \\
0.55 \\
0.53 \\
0.50\end{array}$ & $\begin{array}{l}(116) \\
(138) \\
(133) \\
(129) \\
(129) \\
(128) \\
(125)\end{array}$ & $\begin{array}{l}0.47 \\
0.49 \\
0.55 \\
0.49 \\
0.49 \\
0.49 \\
0.50\end{array}$ & $\begin{array}{l}(78) \\
(99) \\
(96) \\
(97) \\
(96) \\
(94) \\
(93)\end{array}$ \\
\hline
\end{tabular}

father's and mother's height allowing unequal coefficients were fitted and this did not result in an improved prediction of the child's height (Appendix, Table A). The adequacy of the linear regression was tested at each age, by fitting a quadratic term and seeing if the prediction was improved. The linear model was found to be adequate (Appendix, Table B). Possible differences between studies were also looked for. At each age a model with a linear regression coefficient and 'main effects' terms for differences between studies was fitted. The model without the between-studies effects was found to be adequate (Appendix, Table B).

The residuals around the final simple linear regression were then examined; they were approximately normally distributed, with approximately constant variance.

We proceed, therefore, using a linear regression equation of child's height on mid-parent height, all studies pooled, at each age separately. We now wish to see if we can legitimately combine these regressions so as to obviate the necessity for a different chart at each age. It turns out that between ages 2 and 9 we can indeed do so.

Let $\sigma_{\mathrm{s}}$ be the residual standard deviation about the regression, and $\hat{\sigma}_{\mathrm{s}}$ its estimated value. If the correlation coefficients between child and mid-parent height are the same at each age, then, since the standard deviation of $x$ is identical for all ages, the ratio $\beta / \sigma_{\mathrm{s}}$ is the same at each age.

The correlation coefficients from 1 month of age to 9 years are given in Table II. No trend is evident over the age range 2 to 9 (and indeed little from age 1.0 or 1.5). The average correlation coefficients from 2 to 9 are 0.53 for the boys and 0.49 for the girls.

Table III was then constructed. The values of $a, b$ (the least squares estimates of $\alpha$ and $\beta$ ), and $\hat{\sigma}_{s}$ were calculated for each age, and the ratio $b / \hat{\sigma}_{s}$ was found to be nearly constant, as predicted. The average value of this ratio, designated $K$, was found. 


\section{TABLE III}

Characteristics of Regression Lines of Child's Height on Mid-Parent Height (for designation of constants see text)

\begin{tabular}{|c|c|c|c|c|c|c|}
\hline Age (yr.) & $a$ & $\boldsymbol{b}$ & $\hat{\sigma}_{\mathbf{s}}$ & $b / \boldsymbol{\sigma}_{\mathbf{8}}$ & $a^{\prime}$ & $\hat{\sigma}_{R}$ \\
\hline $\begin{array}{r}\text { Boys } \\
2 \cdot 0 \\
3 \cdot 0 \\
4 \cdot 0 \\
5 \cdot 0 \\
6 \cdot 0 \\
7 \cdot 0 \\
8 \cdot 0 \\
9 \cdot 0\end{array}$ & $\begin{array}{l}38 \cdot 7 \\
35 \cdot 6 \\
39 \cdot 1 \\
29 \cdot 0 \\
37 \cdot 8 \\
35 \cdot 9 \\
39 \cdot 3 \\
40 \cdot 1\end{array}$ & $\begin{array}{r}0.29 \\
0.36 \\
0.38 \\
0.48 \\
0.47 \\
0.51 \\
0.53 \\
0.56 \\
\mathrm{~K}=\end{array}$ & $\begin{array}{l}2 \cdot 70 \\
2 \cdot 84 \\
3 \cdot 25 \\
3 \cdot 63 \\
4 \cdot 12 \\
4 \cdot 12 \\
4 \cdot 51 \\
4 \cdot 86 \\
0 \cdot 119\end{array}$ & $\begin{array}{l}0 \cdot 107 \\
0 \cdot 126 \\
0 \cdot 117 \\
0 \cdot 132 \\
0 \cdot 113 \\
0 \cdot 125 \\
0 \cdot 117 \\
0 \cdot 114\end{array}$ & $\begin{array}{r}11 \cdot 17 \\
9 \cdot 06 \\
7 \cdot 95 \\
7 \cdot 02 \\
6 \cdot 34 \\
6 \cdot 06 \\
5 \cdot 94 \\
5 \cdot 92\end{array}$ & $\begin{array}{l}2 \cdot 80 \\
3 \cdot 25 \\
3 \cdot 65 \\
4 \cdot 02 \\
4 \cdot 36 \\
4 \cdot 63 \\
4 \cdot 86 \\
5 \cdot 07\end{array}$ \\
\hline $\begin{array}{c}\text { Girls } \\
2 \cdot 0 \\
3 \cdot 0 \\
4 \cdot 0 \\
5 \cdot 0 \\
6 \cdot 0 \\
7 \cdot 0 \\
8 \cdot 0 \\
9 \cdot 0\end{array}$ & $\begin{array}{l}42 \cdot 0 \\
45 \cdot 5 \\
44 \cdot 3 \\
35 \cdot 6 \\
43 \cdot 6 \\
43 \cdot 6 \\
48 \cdot 5 \\
43 \cdot 1\end{array}$ & $\begin{array}{r}0.27 \\
0.29 \\
0.34 \\
0.44 \\
0.43 \\
0.46 \\
0.47 \\
0.53 \\
K\end{array}$ & $\begin{array}{l}2 \cdot 55 \\
2 \cdot 63 \\
3 \cdot 05 \\
3 \cdot 35 \\
3 \cdot 82 \\
4 \cdot 22 \\
4 \cdot 26 \\
4 \cdot 76 \\
0 \cdot 113\end{array}$ & $\begin{array}{l}0 \cdot 106 \\
0 \cdot 110 \\
0 \cdot 113 \\
0 \cdot 131 \\
0 \cdot 112 \\
0 \cdot 110 \\
0 \cdot 110 \\
0 \cdot 112\end{array}$ & $\begin{array}{r}10 \cdot 86 \\
8 \cdot 90 \\
7 \cdot 81 \\
6 \cdot 99 \\
6 \cdot 34 \\
6 \cdot 09 \\
6 \cdot 02 \\
6 \cdot 09\end{array}$ & $\begin{array}{l}2 \cdot 88 \\
3 \cdot 34 \\
3 \cdot 75 \\
4 \cdot 13 \\
4 \cdot 48 \\
4 \cdot 76 \\
5 \cdot 01 \\
5 \cdot 23\end{array}$ \\
\hline
\end{tabular}

The estimates of the residual standard deviations $\hat{\delta}_{\mathbf{s}}$ from the sample however are not the most appropriate for actual use in our standards, since they are derived from a relatively small and unrepresentative sample, measured by only four measurers. The standard deviations appropriate for the population and a wider range of measurers would be larger. Hence we have used the standard deviations given in the current British standards (Tanner et al., 1966), diminished by the estimate of parent-child correlation, according to the relation $\hat{\sigma}_{R}{ }^{2}=\left(1-r^{2}\right) \sigma^{2}$, where $\hat{\sigma}_{R}$ is the estimated residual standard deviation, $\sigma$ the standard deviation from the British standards, and $r$ the average correlation coefficient of child's height with mid-parent height. The correctness of this calculation depends on $r$ being approximately the same at each age, as demonstrated in Table II, and the numbers in the sample being large.

The charts shown in Fig. 1 and 2 were then constructed. At each age the equation $y / \hat{\sigma}_{R}=a^{1}+K x$ was fitted. The values of $a^{\prime}$ were estimated by $a^{\prime}=$ $\bar{y} / \hat{\boldsymbol{\sigma}}_{R}-K \bar{x}$ (Table III), where the values of $\bar{y}$, the mean height at each year of age, were taken as the 50th centiles of the British standards (Tanner et al., 1966). Since no appropriate British standards exist for $\bar{x}$, mid-parent height, the sample value of $166.9 \mathrm{~cm}$. was used. (This value is $1.3 \mathrm{~cm}$. less than the mid-parent height given

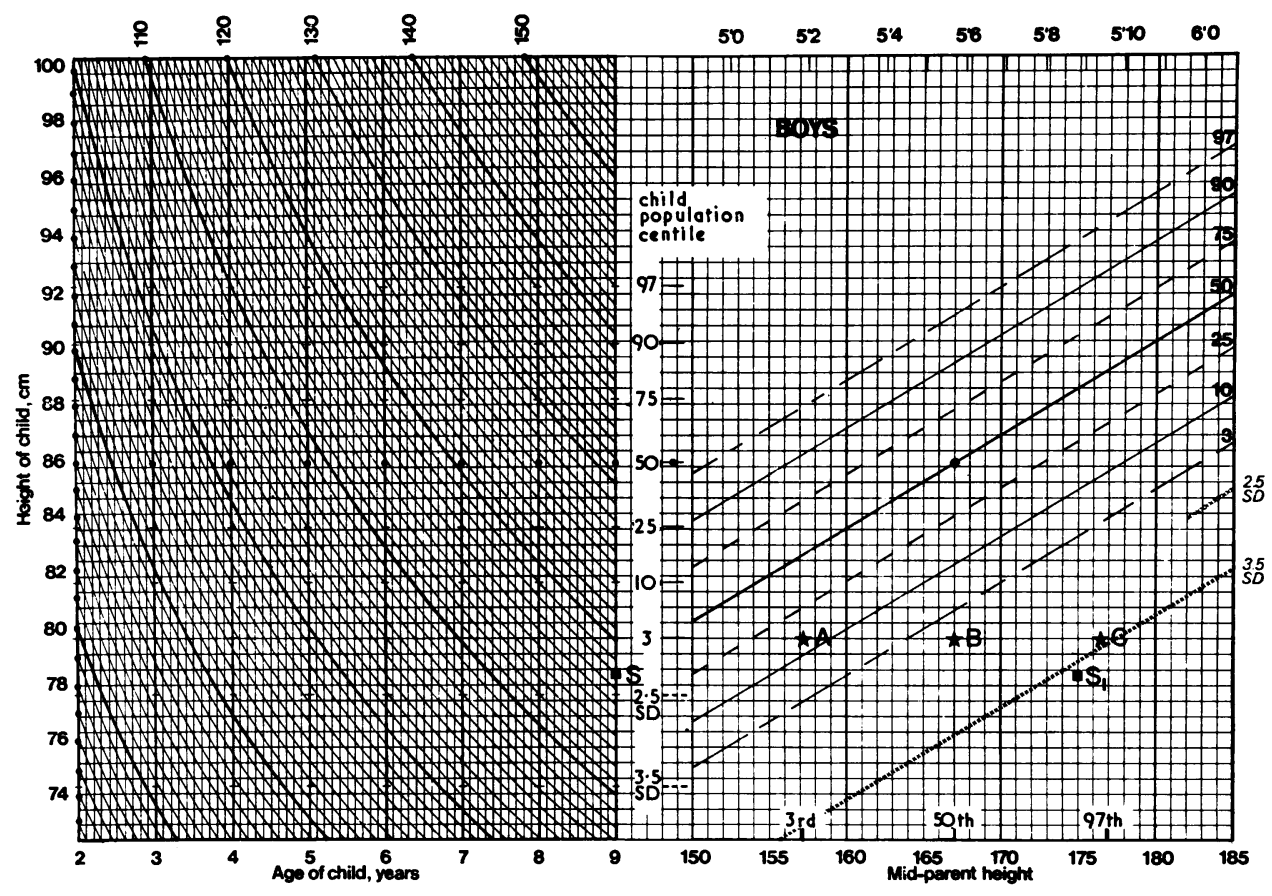

FIG. 1.-Standards for height for boys aged 2 to 9, allowing for mid-parent height. The horizontal lines under child population centile marked 97, 90, 75, 50, 25, 10, 3, 2.5 SD and 3.5 SD represent these values on the 'parent-unknown' standards. Boys $A, B$, and $C$ are at 3rd centile on 'parent-unknown' 1966 standards, with parents averaging respectively $3 r d, 50 t h$, and 97 th centiles. Boy $S$ represents an actual case (see text.) 


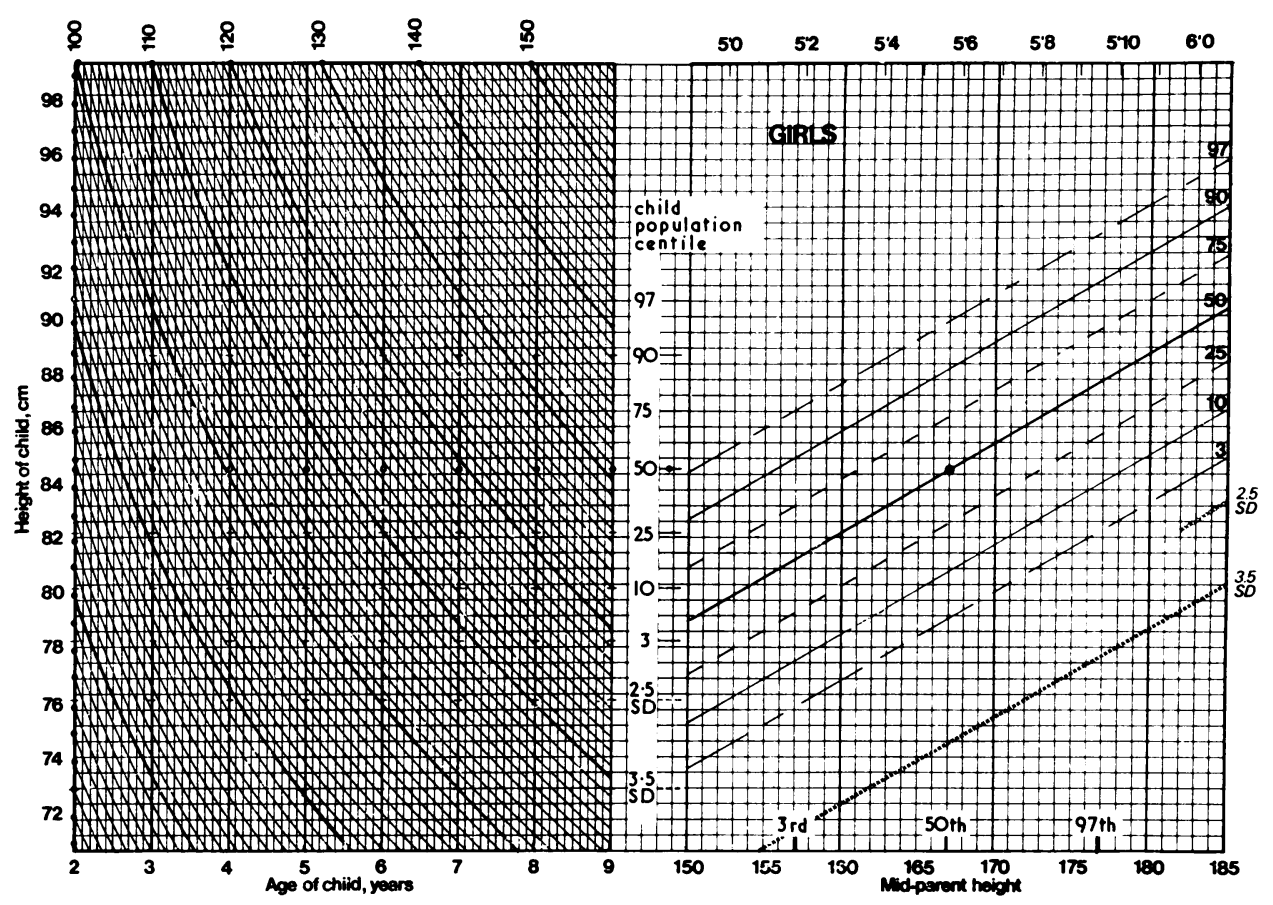

FIG. 2.-Standards for height for girls aged 2 to 9, allowing for mid-parent height.

by the 1966 standards at age 19, and this difference probably just about represents the secular trend from one generation to another at present; thus the child standards and our adult figures are reasonably consistent).

The line $y^{\prime}=\left(y / \hat{\sigma}_{R}-a^{\prime}\right)=K x$ was drawn against the scale of $x$, this defining the values of the scale $y^{\prime}$. The line $y^{\prime}=K x$ is thus the 50th centile of child's height for given mid-parent height. The other centiles were drawn parallel to this, using normal distribution values with a standard deviation of $1 \cdot 0$. The $-2 \cdot 5 \mathrm{SD}$ line is indicated also, and the $-3.5 \mathrm{SD}$ line drawn in.

We now need to express the scales for actual height $y$, in terms of $y^{\prime}$. These scales are different for each age. For each age scale the values of $y$ are given by $y=\left(y^{\prime}+a^{\prime}\right) \hat{\sigma}_{R^{\prime}}$. Thus the mean heights at each age (British standards) correspond to the value of $y^{\prime}$ at mean mid-parent height (i.e. the value $\bar{y}^{\prime}=K \bar{x}$ ). The age scales on the left of the charts were drawn, and identical values of child's height at each age joined to make the curved lines. The centiles are thus applicable to the range $2 \cdot 0$ to $9 \cdot 0$ years.

\section{Use of Standards}

The simplest way to use the chart is to find first the child's height, interpolating where necessary. Follow the curve till the correct age (also interpolated) is reached. Place a ruler from this point along the horizontal lines across to the right hand portion of the chart; then the point where this crosses the vertical line corresponding to the mid-parent height is the one required. The centile position of this point is then read.

The 3rd, 10th, 25th, 50th, 75th, 90th, and 97th centiles of the 'parent-unknown' standards can be represented on the charts by horizontal lines. They are indicated in the centre of the chart, and on the left-hand side by the short horizontal lines $(3,10,25,75,90,97)$ and the solid circles (50th). If the child's height has been plotted on the 1966 standard height-for-age chart and his centile position determined, these lines can be used instead of the actual height measurements. This way of using the new charts is not so accurate as using the measurements themselves however, and is inapplicable to very small or very large children.

Note that the child who stays at the same centile for height as he gets older plots at the same place at every age on the new charts. If a child rises through the height-for-age centiles then his position on the new chart also rises; and vice versa.

The increased precision of the new standards can be seen by considering the three boys A, B, and C (Fig. 1), all exactly at the 3rd centile on the old standards. ' $A$ ' has parents whose average height is itself at the $3 \mathrm{rd}$ centile. His true centile is about the 20th. ' $B$ ' has parents of exactly average height; he drops to considerably below the 3rd centile and should clearly be regarded as abnormal until shown otherwise. Child ' $C$ ' has very tall parents, at the 97 th centile, and he is now seen to be very dwarfed indeed. 


\section{Standards for Children's Height at Ages 2-9Years Allowing for Height of Parents}

Conversely the chart shows that for a boy with 3rd centile parents to be at the 3rd centile when the parents are allowed for, he must be about $2 \cdot 7 \mathrm{SD}$ below the mean height for his age. A boy with 97th centile parents however is at the 3rd centile, when parents are allowed for, while he is only at the 25th centile in the total population of boys. Thus the parent-unknown standards produce a considerable area of misclassification.

The new standards are particularly useful in the differential diagnosis of genetic small stature (see Tanner, 1971). Typically children with this diagnosis will appear in the triangle bounded above by the 'parentunknown' 3rd centile, to the left by the mid-parent 3rd centile, and below by the parent-allowed-for 3rd centile. In clinical work on short children, the lines representing scores of minus 2.5 and 3.5 standard deviations of height below the mean for given age are sometimes used, to give an idea of whether a child below the 3 rd centile is moderately small or exceedingly small. These lines have also been indicated in the charts. Children may well be between the $2 \cdot 5$ and $3.5 \mathrm{SD}$ lines on the parent-unknown standards and, if they have small parents, be simply genetically small children. But those below the 3.5 $\mathrm{SD}$ line are almost certain to have some other cause for their short stature.

Conversely, a child thought to be only moderately small by reference to parent-unknown standards, may, if he has large parents, actually be wholly below normal limits. An actual case is the boy marked $S$ in Fig. 1. He was diagnosed as simply a (normal) small child but failed to secrete growth hormone on insulin hypoglycaemia and doubled his rate of growth when given human growth hormone. On review, since his true diagnosis was clearly isolated growth hormone deficiency, it became apparent that for his parent's height he was indeed below 3.5 standard deviation $S_{1}$.

In Fig. 3 seven healthy boys are plotted. Their positions on the parent-unknown charts are shown in Fig. 4. Five boys of the London longitudinal sample fell outside the 3rd and 97th limits at one or more ages 4 to 9 on the parent-unknown chart. Four of these $(114,46 ; 157,47)$ came within the limits when parents' height was allowed for. (The father and mother of no. 114 measured $159 \cdot 7$ and $143 \cdot 1 \mathrm{~cm}$.)

Child no. 155 remained outside the 97 th on the new chart, his mid-parent height being close to average. He is plotted at age 9; unlike the other children, his position steadily rose from 4 years (when he was well within normal limits) onwards. $\mathrm{He}$ is in fact a very early maturer with a bone age of $12 \cdot 2$ 'years' at age $9 \cdot 0$ (a degree of advancement considerably beyond normal limits, which are about \pm 2 years). His adolescent peak height velocity was reached at $11 \cdot 5$ years (average is $14 \cdot 0$ ), and he practically ceased growing at $16 \cdot 0$, by which time he had fallen back to the 75th centile. It is of course possible to plot a child's height for his bone age on the

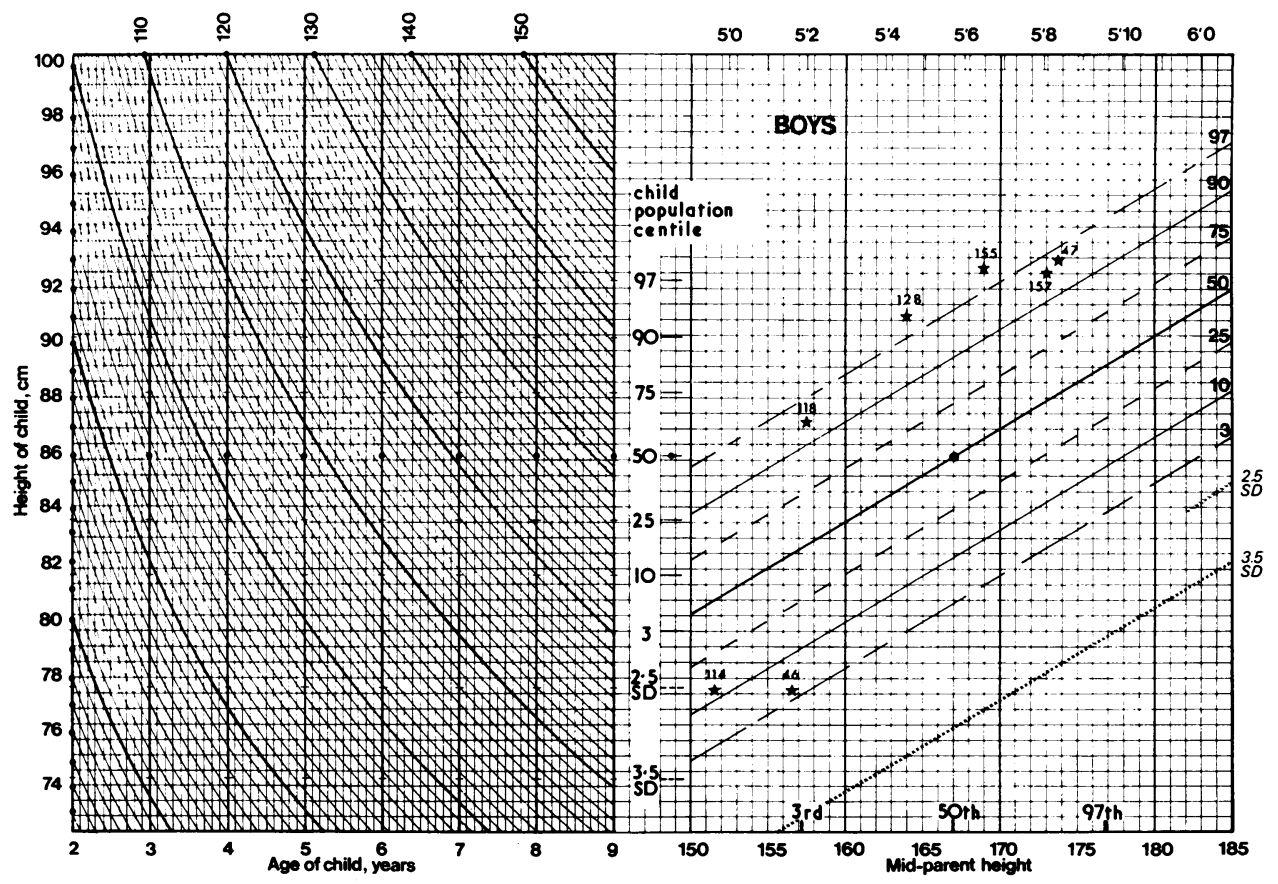

FIG. 3.-Four boys $(114,46,47,157)$ whose height was outside the 97 th or 3rd centiles on parent-unknown standards (horizontal lines) and changed to within these limits on the new standards; one boy (155) who remained outside; and 2 boys whose positions were moved towards (118) and across (128) the limits when parental height was considered. 


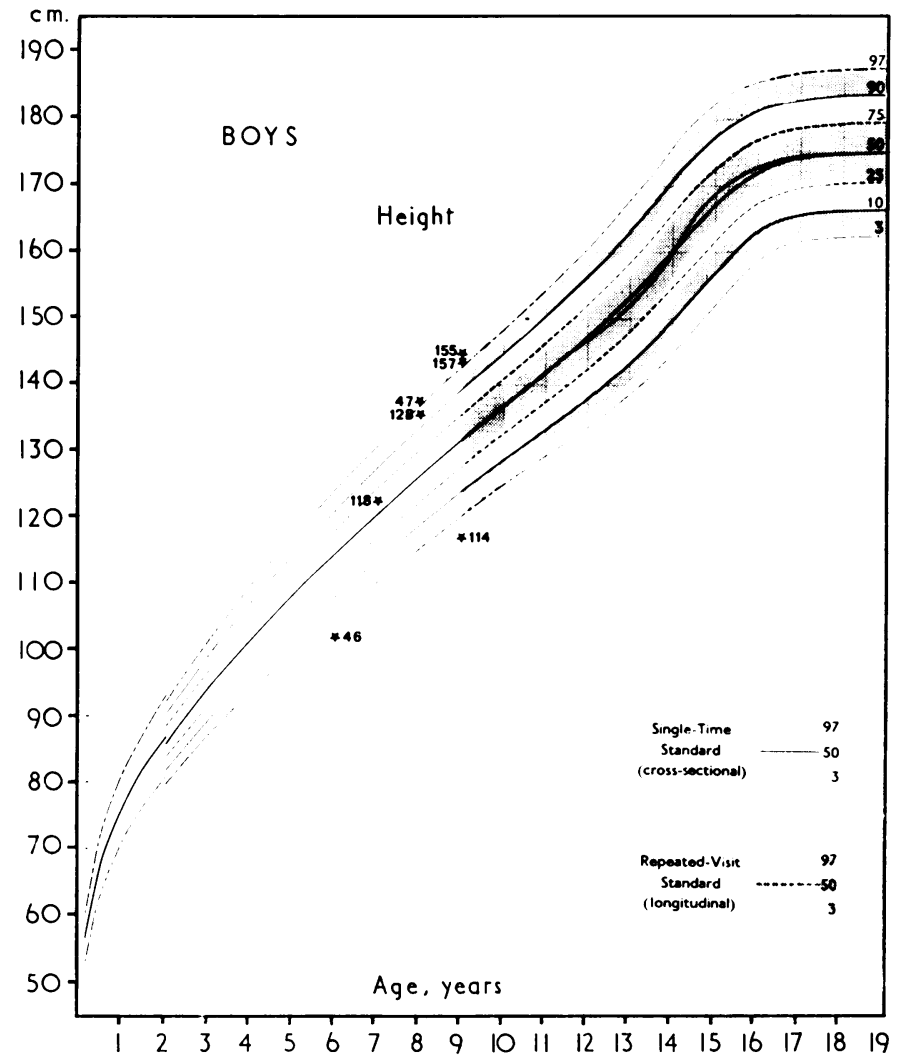

Fig. 4.-Same boys as in Fig. 3, plotted on the standard, 'parent-unknown' charts.

new charts just as on the old ones, provided the bone age falls between 2.0 and 9.0 'years'. It is in this way that the diagnosis growth delay is made in short children who are below normal limits both on the 'parent-unknown' and parent-allowed-for charts. In growth delay the bone age is more than two years retarded, but stature is within normal limits (on the parent-unknown charts if parents are of average height or above, on the parentallowed-for charts if the child is also genetically small) when height is plotted at the bone age instead of chronological age.

All the London study boys' records were examined to see if any child was changed from being inside normal limits on the parent-unknown to outside them on the new charts. One such boy was found, No. 128. His father was Irish and of average height $(175 \cdot 1 \mathrm{~cm}$.), but his mother, born in London, of Italian parents, was only at the 3rd centile $(151.7 \mathrm{~cm}$.) for British women. It is possible, but by no means certain, that his mother was stunted by poor social circumstances in infancy. When fully grown this boy ended considerably above the 97th centile. His bone age was within a year of his chronological age from 5 to 9 .

The last child plotted, No. 118 , is similar to 128 in that he moves nearer to, though does not pass beyond, the boundaries of normal when his parents are allowed for. Both his parents are immigrants from North Italy and are short. The boy is a little advanced, having a bone age about $1 \frac{1}{2}$ years greater than chronological age. In agreement with this he ends with a mature height at the 30 th centile.

\section{Discussion}

Age of parents. The standards are appropriate for parents at an age before diminution of their height sets in. When proper techniques of measurement are used, including gentle upward pressure on the mastoid process to stretch the subject to full height, then shrinking in the average person only starts at age 45 to 50 . When the parents are actually measured an approximate correction can be made by adding $1.5 \mathrm{~cm}$. at ages 45 to 55 and $3.0 \mathrm{~cm}$. at ages above 55 . When height is only that reported by the parents the maximal young adult height should be used. 
Technique of measurement of child. The standards, like the British 'parent-unknown' standards, are appropriate for children measured by a trained and careful measurer using a standard technique and a standard and accurate instrument, (see Tanner, 1971). Unless the child is properly positioned and stretched to maximal height by gentle upward pressure and encouragement he may easily be recorded as 1 or $2 \mathrm{~cm}$. below his proper height.

Interaction of parents. In theory it is possible that the prediction of child's beight might be different according to whether the father and mother were similar in height or differed greatly. In testing the adequacy of mid-parent height, however, we implicitly tested whether the difference between the two parents had an effect, with negative results. It is also possible that the prediction of child's height is not an additive function of father's and mother's height. We tested whether the inclusion of the interaction term father's $\times$ mother's height in the multiple regression significantly improved prediction. It did not do so. However it takes a much larger quantity of data to demonstrate non-additivity of the relatively small amount to be expected; so our result should not be taken to exclude it.

Prediction of 'target' adult height of child. In children undergoing treatment or under obsarvation, it is often useful to have an idea of their range of 'target' adult height; that is to say, the range within which aduit height might be expected to be on genetical grounds. On the height-for-age charts we now routinely plot the mother's and father's height centiles, at the end of the height line, i.e. age 19 (on a boy's chart the father's height is plotted directly and the mother's after the addition of the mean adult sex difference, that is $13 \mathrm{~cm}$. or 5 in.; the reverse is done when plotting the father's height on a girl's chart). The 3rd to 97th centile range of mid-parent height is $20 \mathrm{~cm}$. and on the assumption of an adult parentchild height correlation of $0 \cdot 5$, the residual $3 \mathrm{rd}$ to 97th range for the child when parents are known is $17 \mathrm{~cm}$. Thus the expected range can be marked by taking the mid-point of father's and mother's plots (giving the mid-parent centile, though not actual height) and laying off $8.5 \mathrm{~cm}$. above and below it.

Socio-economic circumstances and height prediction. If the parents failed to achieve their genetical potential in height owing to restricted economic circumstances, then the prediction of the children's heights would be expected to be too low, provided they, in their turn, were brought up in better conditions. Thus in some parts of Britain we might expect the correlations of children and parents to be smaller in the lower socio-economic classes than in the higher ones. Indeed, given enough data, the difference or the lack of it in the correlations might indicate the degree to which the social class height differences were genetic or environmental in origin (see Tanner, 1966). Our data are insufficient however to throw light on this.

Mother-daughter, mother-son, etc., correlations. The correlation coefficients between mother-daughter, mother-son, father-daughter, and father-son from 1 month to 9 years are given in Table IV. Contrary to some reports in the literature (Tanner and Israelsohn, 1963) but in agreement with others (Livson, McNeil, and Thomas, 1962; Garn and Rohmann, 1966; Goldstein, 1970), there is no systematic difference between the four relations.

\section{TABLE IV}

Correlations Between Children's Heights and Parental Heights (Pooled data of London, Brussels, Stockholm, and Zürich, Longitudinal studies)

\begin{tabular}{l|c|c|c|c}
\hline \multicolumn{2}{c|}{ Supine length $0.083-2.0$ yr. } & Stature 3.0-9.0 yr. \\
\hline Age (yr.) & $\begin{array}{c}\text { Mother- } \\
\text { Daughter }\end{array}$ & $\begin{array}{c}\text { Mother- } \\
\text { Son }\end{array}$ & $\begin{array}{c}\text { Father- } \\
\text { Daughter }\end{array}$ & $\begin{array}{c}\text { Father- } \\
\text { Son }\end{array}$ \\
\hline 0.083 & 0.29 & 0.22 & 0.20 & 0.16 \\
0.25 & 0.36 & 0.30 & 0.25 & 0.31 \\
0.50 & 0.40 & 0.31 & 0.34 & 0.43 \\
0.75 & 0.38 & 0.37 & 0.36 & 0.33 \\
1.0 & 0.37 & 0.37 & 0.31 & 0.42 \\
1.5 & 0.34 & 0.38 & 0.33 & 0.41 \\
2.0 & 0.46 & 0.36 & 0.36 & 0.45 \\
\hline 3.0 & 0.41 & 0.48 & 0.41 & 0.46 \\
4.0 & 0.44 & 0.41 & 0.40 & 0.45 \\
5.0 & 0.46 & 0.46 & 0.43 & 0.49 \\
6.0 & 0.46 & 0.43 & 0.40 & 0.43 \\
7.0 & 0.44 & 0.44 & 0.40 & 0.47 \\
8.0 & 0.43 & 0.42 & 0.43 & 0.46 \\
9.0 & 0.44 & 0.43 & 0.44 & 0.42 \\
& & & & \\
\hline
\end{tabular}

We wish to acknowledge permission to use the data from the Brussels study (Professor M. Graffar and Dr. M. Asiel), the Stockholm study (Professor P. Karlsberg), and the Zürich study (Professor A. Prader) and to thank many members of the International Children's Centre Co-ordinated Longitudinal Studies Group for their helpful criticisms. We are most grateful also for financial support from the Nuffield Foundation, to the Department of Growth and Development; and from the NATO Scientific Affairs Division, to the International Children's Centre.

\section{REFERENCES}

Garn, S. M., and Rohmann, C. C. (1966). Interaction of nutrition and genetics in the timing of growth and development. Pediatric Clinics of North America, 13, 353.

Goldstein, H. (1970). Factors influencing the height of seven-yearold children. Results from the National Child Development Study. Human Biology. In press. 
Livson, N., McNeill, D., and Thomas, K. (1962). Pooled estimates of parent-child correlations in stature from birth to maturity. Science, 138, 818.

Tanner, J. M. (1966). Galtonian eugenics and the study of growth: the relation of body size, intelligence test score, and social circumstances in children and adults. Eugenics Review, 58, 122. (1971). Physical growth and development. In Textbook of Paediatrics. Ed. by J. O. Forfar and G. C. Arneil. Edinburgh. Livingstone,

—, Goldstein, H., Graffar, M., Asiel, M., Karlberg, P., Prader, A., and Sempé, R. (1968). Standards for children's height at ages 3 to 9 adjusted for height of parents. Proceedings of International Paediatrics Congress, Mexico City, December 1968.

- and Israelsohn, W. J. (1963). Parent-child correlations for body measurements of children between the ages one month and seven years. Annals of Human Genetics, 26, 245.

- Whitehouse, R. H., and Takaishi, M. (1966). Standards from birth to maturity for height, weight, height velocity and weight velocity: British children 1965. Archives of Disease in Childhood, 41, 454, 613.

\section{Appendix Table A}

The multiple regression:

Child's height $=a+\beta$ (Mother's height) $+\gamma$ (Father's height) was fitted at each age and $F$ tests made of the hypothesis that $\beta$ and $\gamma$ were equal. The values below are all non-significant at the $10 \%$ level; hence the hypothesis is not rejected.

\begin{tabular}{|c|c|c|c|c|}
\hline \multirow{2}{*}{ Age (yr.) } & \multicolumn{2}{|c|}{ Boys } & \multicolumn{2}{|c|}{ Girls } \\
\hline & $\mathbf{F}$ & D.F. & $\mathbf{F}$ & D.F \\
\hline $\begin{array}{l}3 \\
4 \\
5 \\
6 \\
7 \\
8 \\
9\end{array}$ & $\begin{array}{l}2 \cdot 4 \\
0 \cdot 3 \\
0.3 \\
0 \cdot 0 \\
0 \cdot 1 \\
0 \cdot 4 \\
0.5\end{array}$ & $\begin{array}{l}1 ; 113 \\
1 ; 135 \\
1 ; 130 \\
1 ; 126 \\
1 ; 126 \\
1 ; 125 \\
1 ; 122\end{array}$ & $\begin{array}{l}1 \cdot 0 \\
0 \cdot 0 \\
0 \cdot 1 \\
0 \cdot 1 \\
0 \cdot 1 \\
0 \cdot 7 \\
0 \cdot 3\end{array}$ & $\begin{array}{l}1 ; 75 \\
1 ; 96 \\
1 ; 93 \\
1 ; 94 \\
1 ; 93 \\
1 ; 91 \\
1 ; 90\end{array}$ \\
\hline
\end{tabular}

\section{Appendix Table B}

Tests for Adequacy of Simple Linear Regression of Height on Mid-Parent Height, studies pooled

At each age, for both sexes, a model was fitted with 'main effects' terms for differences between studies, together with linear and quadratic regression coefficients. The adequacy of a model without the quadratic coefficient was tested. The adequacy of a model with a single linear regression coefficient was tested against the model with a linear regression coefficient and between-studies main effects.

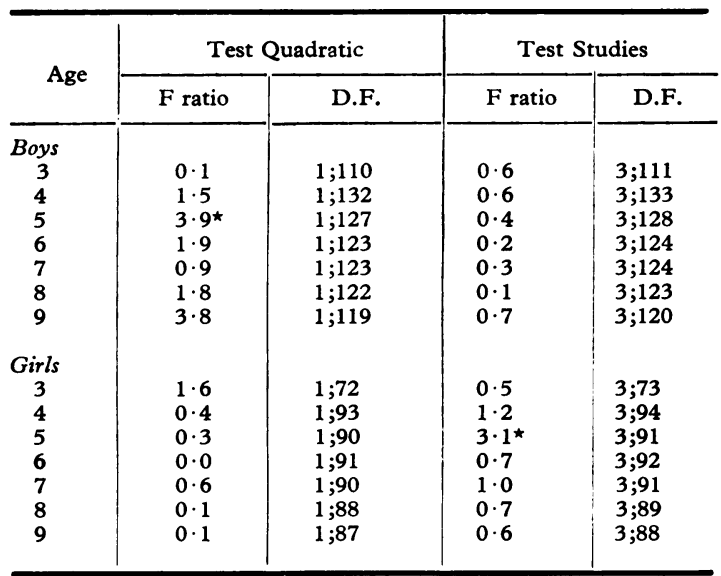

Significance levels $\star 0.05>p>0.01$. Otherwise $p>0.05$

Correspondence to Professor J. M. Tanner, Department of Growth and Development, Institute of Child Health, 30 Guilford Street, London W.C.1. 